Operable pancreatic cancer is characterized by a high risk of recurrence. Efforts are made to incorporate new therapies. Throughout the world there is a lack of uniform recommendations concerning the adjuvant treatment of pancreatic cancer patients, due to confusing evidence-based data. The patients recruited to clinical trials differ from the population of patients treated in everyday practice. These differences have an influence on tolerance of treatment, toxicity and results of therapy. The decision on administration of adjuvant treatment is made individually and differs from center to center. A review of the literature concerning both results and tolerance of postoperative chemoradiotherapy of pancreatic cancer patients is presented.

Key words: pancreatic cancer, adjuvant chemoradiotherapy, radiotherapy, gemcitabine, 5-fluorouracil, toxicity.

Contemp Oncol (Pozn) 2016; 20 (2): 102-108 DOI: $10.5114 /$ wo.2016.60066

\section{Chemoradiotherapy for locally advanced pancreatic cancer patients: is it still an open question?}

\author{
Emilia Sawicka $^{1}$, Anna Mirończuk ${ }^{1}$, Marek Z. Wojtukiewicz ${ }^{2,3}$, Ewa Sierko ${ }^{2,3}$
}

${ }^{1}$ Scientific Students Association affiliated with the Department of Oncology,

Medical University of Bialystok, Poland

${ }^{2}$ Department of Oncology, Medical University of Bialystok, Poland

${ }^{3}$ Comprehensive Cancer Center, Bialystok, Poland

\section{Introduction}

In Poland, pancreatic cancer represents $2.3 \%$ of all malignant tumors in females and about $2.4 \%$ in males, being accordingly the sixth and seventh cause of death from cancer. Pancreatic cancer mortality ranges from 5 to 8 cases per 100000 inhabitants yearly $(5.35 \%$ in female, $4.5 \%$ in male inhabitants). With an estimated 232000 new cases per year, pancreatic cancer is among the most common malignancies worldwide. Moreover, it is one of the most lethal cancers, as indicated by a mortality rate of $98 \%$ [1]. The majority of pancreatic cancers occur after 55 years of age, slightly more often in the male population [2]. As few as 20-30\% of pancreatic cancer patients may be offered radical surgery [3]. So far the results of surgical treatment alone are highly unsatisfactory [4]. The disease is characterized by a high risk of recurrence in the tumor bed [5]. It is known that $80 \%$ of disease progression will occur within 12 months after surgery [6]. Effective treatment of pancreatic cancer patients is thus an important oncological challenge. Therefore, efforts are made to incorporate new therapies in the adjuvant setting, including chemotherapy (CT) alone or chemo-radiotherapy (CT-RT) [3]. What is more the delivery of genetic material to cells allows for a variety of therapeutic concepts. To improve survival for patients with pancreatic cancer biological modulators such as type-I interferons (IFNs) are being added to the treatment. Engineered agents based on synthetic biology are under clinical investigation as well. Among newer immune therapies, Gl-4000 consists of 4 different targeted molecular immunogens, each containing a different Ras protein (antigen) encoded by the most commonly found mutant RAS genes in solid tumors. RAS mutations exist in over $90 \%$ of pancreatic ductal adenocarcinomas.

Throughout the world, uniform recommendations concerning the adjuvant treatment of pancreatic cancer patients are lacking, due to confusing evidence-based data. There are studies which showed a satisfactory outcome in a group of patients $[7,8]$, but other studies did not reveal sufficient efficacy of adjuvant therapy $[9,10]$. The decision on adjuvant treatment administration is made individually and differs from center to center.

Most malignant pancreatic cancers are ductal adenocarcinomas [11]. The administration of concurrent CT-RT in an adjuvant setting in pancreatic cancer patients has shown conflicting results over the last two decades and the true impact of the postoperative treatment remains uncertain [12]. Surgery is the only curative treatment for pancreatic cancer patients, but long-term survival after surgical resection of pancreatic cancer patients is less than $20 \%$ [13]. Local recurrence with or without distant metastases occurred in $40-50 \%$ of patients who underwent surgery alone, whereas distant metas- 
tases were diagnosed in $49 \%$ of patients $[5,14]$. That is why, in most cases, radical surgery in pancreatic cancer patients is followed by adjuvant CT alone, which is the current standard in Europe based on the results of the ESPAC-1, CONKO, and ESPAC-3 studies. Radiochemotherapy is also incorporated and is considered to be the optimal therapy in North America based on the results of the Gastrointestinal Tumor Study Group (GITSG) and Radiation Therapy Oncology Group (RTOG) studies, due to the unsatisfactory results of CT alone [15]. A recently published Bayesian network meta-analysis revealed that $\mathrm{CT}$ with 5-fluorouracil (5-FU) or gemcitabine is the optimal adjuvant treatment for pancreatic adenocarcinoma and reduces mortality after surgery by about a third. Chemoradiation followed by $\mathrm{CT}$ is less effective in prolonging survival and more toxic than CT alone [16].

\section{Results of adjuvant chemo-radiotherapy}

The first trial of CT-RT was initiated in the United States by the GITSG in 1974 [7] (Table 1). Patients who were treated with a split-course radiotherapy schedule (40 Gy) combined with CT (bolus 5-FU) during the first and the last week of radiation therapy, which was continued later on, had significantly better results of treatment in compar- ison to patients who underwent adjuvant CT alone - in terms of median overall survival (OS) of 21 months vs. 11 months, 2 -year survival of $43 \%$ vs. $18 \%$ and 5 -year survival of $19 \%$ vs. $5 \%$, respectively. The trial was the basis for the introduction of adjuvant CT-RT as a standard of care in the United States and Canada as a postoperative regimen in pancreatic cancer patients over the last 30 years [17]. However, in the evidence-based medicine era, it is important to note that the trial was low-powered, because of the small number of patients entered in the GITSG study. Adverse aspects of the study included the prolonged 8-year accrual time of study participants, the lack of a central standardized quality assurance for radiotherapy, and the delay in starting adjuvant treatment after surgery. Furthermore, only $9 \%$ of patients received the planned 2-year maintenance $\mathrm{CT}$, and the radiation dose was low (split course suboptimal according to modern standards).

It should also be noted that the technical revolution in radiotherapy, ongoing since the 1970 s, offers the patients a better dose distribution with better dose coverage of the clinical target volume as well as sparing organs at risk.

The European Organization for Research and Treatment of Cancer (EORTC) 40891 trial was conducted between 1987 and 1995 by the Gastrointestinal Tract Cancer Cooper-

Table 1. Randomized trials evaluating adjuvant therapy in pancreatic cancer

\begin{tabular}{|c|c|c|c|c|c|c|}
\hline \multirow[t]{2}{*}{ References } & \multirow[t]{2}{*}{ Trial } & \multirow{2}{*}{$\begin{array}{c}\text { Year } \\
\text { published }\end{array}$} & \multirow[t]{2}{*}{ No. } & \multirow[t]{2}{*}{ Treatment arms } & \multicolumn{2}{|c|}{ Survival } \\
\hline & & & & & $\begin{array}{l}\text { Median } \\
\text { (months) }\end{array}$ & os \\
\hline$[7]$ & GITSG & 1985 & 43 & $\begin{array}{c}\text { observation } \\
\text { vs. 5-FU CT-RT, 5-FU CT }\end{array}$ & $\begin{array}{l}11 \\
21\end{array}$ & $\begin{array}{l}2-y r 18 \% \\
2-y r 43 \%\end{array}$ \\
\hline$[18,19]$ & EORTC & $\begin{array}{l}1999,2007 \\
\text { (follow up) }\end{array}$ & 218 & $\begin{array}{l}\text { observation } \\
\text { vs. } 5 \text {-FU CT-RT }\end{array}$ & $\begin{array}{l}19 \\
25\end{array}$ & $\begin{array}{l}5-y r 22 \% \\
5-y r 25 \%\end{array}$ \\
\hline$[9,23]$ & $\begin{array}{c}\text { ESPAC-1 } \\
\text { (individual } \\
\text { treatment groups) }\end{array}$ & 2004 & 289 & $\begin{array}{c}\text { 5-FU/folinic acid CT } \\
\text { vs. 5-FU CT-RT } \\
\text { vs. 5-FU/folinic acid CT, 5-FU CT-RT, } \\
\text { vs. observation }\end{array}$ & $\begin{array}{l}21.6 \\
13.9 \\
19.9 \\
16.9\end{array}$ & $\begin{array}{l}5-y r \quad 29 \% \\
5-y r \quad 7 \% \\
5-y r 13 \% \\
5-y r 11 \%\end{array}$ \\
\hline [29] & RTOG-9704 & $\begin{array}{l}2008,2011 \\
\text { (follow up) }\end{array}$ & 451 & $\begin{array}{l}\text { 5-FU CT, 5-FU CT-RT, 5-FU CT } \\
\text { vs. Gem CT, 5-FU CT-RT, Gem CT }\end{array}$ & $\begin{array}{l}16.9 \\
20.5\end{array}$ & $\begin{array}{l}5-y r 18 \% \\
5-y r 22 \%\end{array}$ \\
\hline$[20,21]$ & $\begin{array}{l}\text { The Johns Hopkins } \\
\text { Hospital }\end{array}$ & 2008 & 616 & $\begin{array}{l}\text { 5-FU CT-RT } \\
\text { vs. observation }\end{array}$ & $\begin{array}{l}21.2 \\
14.4\end{array}$ & $\begin{array}{l}5-y r \\
5-y r \\
5-15.4\end{array}$ \\
\hline$[12]$ & $\begin{array}{l}\text { EORTC } 40013 \\
\text { Phase II/III }\end{array}$ & 2010 & 90 & $\begin{array}{c}\text { Gem CT } \\
\text { vs. Gem CT, Gem CT-RT }\end{array}$ & $\begin{array}{l}24.4 \\
24.3\end{array}$ & $\begin{array}{l}2-y r 50.2 \\
2-y r 50.6\end{array}$ \\
\hline [22] & $\begin{array}{c}\text { Johns Hopkins } \\
\text { Hospital and Mayo } \\
\text { Clinic }\end{array}$ & 2010 & 1091 & $\begin{array}{l}\text { observation } \\
\text { vs. } 5 \text {-Fu CT-RT }\end{array}$ & $\begin{array}{l}15.5 \\
21.1\end{array}$ & 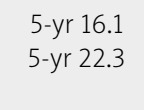 \\
\hline [35] & JASPAC-01 & 2012 & 385 & $\begin{array}{c}\text { S-1 CT } \\
\text { vs. Gem CT }\end{array}$ & & $\begin{array}{l}2-y r 70 \\
2-y r\end{array} 53$ \\
\hline [8] & Kumar et al. & 2014 & 343 & $\begin{array}{l}\text { observation } \\
\text { vs. Gem CT, } \\
\text { vs. } 5 \text {-FU CT-RT }\end{array}$ & $\begin{array}{l}13 \\
23 \\
26\end{array}$ & \\
\hline$[14,32]$ & CONCO 001 & $\begin{array}{l}\text { 2007, } 2013 \\
\text { (follow up) }\end{array}$ & 368 & $\begin{array}{c}\text { Gem CT } \\
\text { vs. observation }\end{array}$ & $\begin{array}{l}22.1 \\
20.2\end{array}$ & $\begin{array}{c}10-y r \quad 12.2 \% \\
10-y r 7.7 \%\end{array}$ \\
\hline [30] & ESPAC-3 & 2009 & 1088 & $\begin{array}{c}\text { Gem CT } \\
\text { vs. } 5 \text {-FU CT }\end{array}$ & $\begin{array}{c}23.6 \\
23\end{array}$ & $\begin{array}{l}2-y r 49 \\
2-y r 28\end{array}$ \\
\hline
\end{tabular}

CT - chemotherapy; RT - radiotherapy; CT-RT-chemo-radiotherapy; 5-FU - 5-fluorouracil; OS - median overall survival; Gem-gemcitabine; CONCO - Charité Onkologie; EORTC - European Organisation for the Research and Treatment of Cancer; ESPAC - European Study Group for Pancreatic Cancer; GITSG Gastrointestinal Tumor Study Group; JASPAC - Japanese Adjuvant Study Group of Pancreatic Cancer; RTOG - Radiation Therapy Oncology Group 
ative Group [18]. In this study 218 patients after pancreatic cancer resection were randomly assigned to receive external beam split course RT - 40 Gy (two courses of 20 Gy in a 2-week-interval) to the tumor bed and regional lymph nodes, with concurrent continuous infusional $5-\mathrm{FU} 25 \mathrm{mg} / \mathrm{kg}$ (maximal daily dose $-1500 \mathrm{mg}$ ) for 5 days at the beginning of the radiation treatment or observation alone. Depending on toxicity, the second CT course consisted of 3 days of 5-FU in patients with G1 or G2 toxicity, or 5 days of 5-FU when no toxicity occurred. No 5-FU treatment was given when $\mathrm{G} 3$ or $\mathrm{G} 4$ toxicity was primarily observed. The study demonstrated no significant improvement in OS (24.5 vs. 19 months) in the CT-RT arm. Subsequent results of the above-mentioned EORTC trial after 12-year follow-up were published in 2007 [19], and revealed similar OS (1.8 vs. 1.6 years) and a 5 -year survival (25\% vs. $22 \%$ ) in both arms. Thus, again, no benefit for pancreatic cancer patients after adjuvant RT-CT was documented $[18,19]$.

The Johns Hopkins Hospital experience was the largest retrospective analysis reporting the results of an adjuvant CT-RT. From 1991 to 1995, 174 patients were reviewed by a multidisciplinary group. One group of patients was treated with a split-course external beam RT schedule (40-45 Gy) and CT (bolus 5-FU $500 \mathrm{mg} / \mathrm{m}^{2}$ per day) during the first and the last 3 days of radiation therapy, and continued later on as weekly bolus of 5 -FU $\left(500 \mathrm{mg} / \mathrm{m}^{2}\right)$ for 4 months [20]. The other group of patients underwent observation alone. Patients who received adjuvant CT-RT had improved 2-year OS and 5-year OS compared to the patients who were given surgery alone (21.2 vs. 14.4 months; and 20.1\% vs. $15.4 \%$, respectively). A follow-up report (from 1993 to 2005) of 616 patients undergoing resection at the Johns Hopkins Hospital suggested that adjuvant concurrent 5-FU-based CT-RT significantly improves survival [21]. Patients receiving CT-RT experienced improved median (21.2 vs. 14.4 months), 2-year (43.9\% vs. 31.9\%), and 5-year (20.1\% vs. $15.4 \%$ ) survival compared to no administration of CT-RT [21]. Recently, a combined analysis of retrospective experience of the Johns Hopkins Hospital and Mayo Clinic revealed improved OS for those receiving adjuvant therapy (21.1 vs. 15.5 months, respectively) [22].

European Study Group for Pancreatic Cancer-1 (ESPAC-1) was a randomized trial that was conducted to answer several questions about adjuvant therapy for pancreatic cancer patients [23]. After resection, a total of 145 patients were assigned to receive CT-RT or CT-RT followed by adjuvant CT. 144 other patients were administered CT alone or were only observed. The trial's design was complex and treating physicians were allowed to enroll their patients into one of the two parallel randomized arms. The updated analysis of the original study was done by way of comparison using a two-by-two factorial design with participants randomized to groups defined as: observation (no adjuvant therapy); adjuvant CT-RT; adjuvant CT; and CT following adjuvant CT-RT [23]. 145 patients were assigned to receive CT-RT [CT-RT (73 patients) + CT-RT followed by CT (72 patients)], while 144 patients were assigned not to receive CT-RT [CT (75 patients) + observation (69 patients)]. A total of 147 patients were assigned to CT (75 to CT alone and 72 to CT in combination with CT-RT), and 142 did not receive CT alone (69 were assigned to the observation group and 73 to the CT-RT group), according to the two-bytwo design. Patients treated with adjuvant CT-RT were given 20 Gy in 10 daily fractions over 2 weeks with $500 \mathrm{mg} / \mathrm{m}^{2}$ 5-FU intravenously on days $1-3$, repeated after 2 weeks or CT based on folinic acid $\left(20 \mathrm{mg} / \mathrm{m}^{2}\right)$ followed by intravenous 5 -FU $\left(425 \mathrm{mg} / \mathrm{m}^{2}\right)$, days $1-5$ monthly for 6 months. The study demonstrated no significant improvement in OS (15.9 vs. 17.9 months), 2-year survival (29\% vs. 41\%), or 5 -year survival (10\% vs. 20\%) among the 145 patients who were assigned to CT-RT compared to 144 patients without CT-RT. One hundred forty-seven patients receiving CT experienced improved OS (20.1 vs. 15.5 months), 2-year (40\% vs. $30 \%$ ), and 5-year survival (21\% vs. $8 \%$ ) compared to 142 patients who did not undergo CT. The OS was 16.9 months among the 69 patients randomly assigned to observation, 13.9 months among the 73 patients randomly assigned to CT-RT, 21.6 months among the 75 patients randomly assigned to CT, and 19.9 months among the 72 patients randomly assigned to CT-RT followed by CT. The respective 5-year survival estimates were 11\%, 7\%, 29\% and 13\% respectively. It should be noted that this two-by-two trial did not have the statistical power to compare these four groups directly [23]. An updated analysis that included the 289 patients who underwent strict randomization, was reported at a median follow-up of 47 months in 2004 [9], which revealed a benefit in OS with adjuvant CT compared to observation (20.1 vs. 15.5 months), but CT-RT produced a deleterious effect on OS in comparison to observation alone (15.9 vs. 17.9 months).

Due to the ongoing controversy concerning postoperative CT-RT, results from the current phase II/III EORTC 40013 trial are awaited. In the trial, patients following RO resection are randomized between gemcitabine therapy (for 4 months) and CT-RT (two courses of gemcitabine for a duration of 8 weeks, followed by weekly gemcitabine in combination with RT - 50.4 Gy/28 fractions). To date, the randomized phase $\|$ study has not revealed (DFS) or OS benefits. Namely, median OS was 24.4 months in the control arm and 24.3 months in the experimental arm and the 2 -year survival rate was $50.2 \%$ and $50.6 \%$, respectively [12]. Treatment options under clinical evaluation include the following: gemcitabine and capecitabine (ESPAC-4), gemcitabine and erlotinib (CONKO-005), and gemcitabine and erlotinib with or without 5-FU/capecitabine-based CTRT (RTOG-0848). The results of current clinical trials will appear soon [24].

Of note, gemcitabine has been widely employed for unresectable advanced pancreatic cancer based on the results of Burris et al. [25] from a phase III study which documented improved survival in patients receiving gemcitabine compared to those receiving fluorouracil (OS 5.65 vs. 4.42 months) [25]. The efficacy and tolerability of gemcitabine for advanced pancreatic cancer have been confirmed by several subsequent studies (Berlin et al. [26], Rocha Lima et al. [27]), and gemcitabine has become the standard therapy for unresectable pancreatic cancer. These facts led investigators to evaluate gemcitabine in the adjuvant setting for patients with resectable pancreatic cancer [28]. 
The results of two large phase III trials, RTOG 97-04 and ESPAC-3(v2), were recently reported $[29,30]$. In the first study a total of 451 patients were randomized to CT with either 5 -FU (continuous infusion of $250 \mathrm{mg} / \mathrm{m}^{2}$ per day) or gemcitabine (30-minute infusion of $1000 \mathrm{mg} / \mathrm{m}^{2}$ once per week) for 3 weeks prior to or 12 weeks after the CT-RT. Radiation therapy (50.4 Gy) was given simultaneously with continuous infusion of 5-FU [29]. In the ESPAC-3(v2) study 1,088 patients from 16 countries were randomized within 8 weeks after surgery to receive either 5-FU/folinic acid (FA $20 \mathrm{mg} / \mathrm{m}^{2}$ as an intravenous bolus injection followed by 5 -FU, $425 \mathrm{mg} / \mathrm{m}^{2}$ as an intravenous bolus infusion, given $1-5$ days every 28 days) or gemcitabine $\left(1,000 \mathrm{mg} / \mathrm{m}^{2}\right.$ as intravenous an infusion on days $1,8,15$ every 4 weeks) for 6 months. The RTOG 97-04 study documented that substituting gemcitabine for 5 -FU before and after RT combined with 5-FU resulted in better outcomes, in terms of OS (20.5 vs. 16.9 months) and 3-year survival (36\% vs. $21 \%$ respectively). Updated results of a phase III trial presented the impact of addition of gemcitabine to 5-FU in CT-RT on 5-year OS (20.5 vs. 17.1 months, respectively). These findings serve as the basis for the recently activated EORTC/U.S. Intergroup RTOG 0848 phase III adjuvant trial evaluating the impact of CT-RT after completion of a full course of gemcitabine [31]. In turn, a combined analysis of the results of both ESPAC-3(v2) and RTOG 97-04 studies demonstrated no significant difference in survival (OS 23.0 vs. 23.6 months) between adjuvant 5-FU combined with leucovorin and adjuvant gemcitabine [30].

The Charité Onkologie (CONKO)-001 randomized trial of adjuvant CT, conducted from July 1998 to 2004, enrolled a total of 368 pancreatic cancer patients with RO or R1 resection. The patients were randomized to adjuvant CT comprising six cycles of gemcitabine every 4 weeks or observation. Median DFS was significantly better in the gem citabine group (in patients with either R0 or R1 resection) than in the control group (13.4 months vs. 6.9 months) [14]. There was no difference in OS, but it is likely that the difference in OS between the groups would become statistically significant with a longer follow-up and an increasing proportion of deceased patients. However, major drawbacks of this study were the lack of quality control of surgical and pathological procedures as well as the participation of a large number of low-volume centers treating small number of patients [14]. In addition, participants in the observation group were given gemcitabine and other chemotherapy upon relapse of disease. These limit the study's capacity to identify a benefit in overall survival [26]. In a follow-up of the CONKO-001 study the median follow-up time was 136 months. Patients randomized to adjuvant gemcitabine treatment had prolonged 5-year and 10-year OS compared with those randomized to observation alone (20.7\% vs. $10.4 \%, 12.2 \%$ vs. $7.7 \%$, respectively) [32]. These results support the use of gemcitabine as adjuvant chemotherapy in resectable carcinoma of the pancreas.

The evidence for adjuvant CT-RT has been reported in recent literature. At the 2014 ASCO Gastrointestinal Cancers Symposium, Kumar et al. [8], in a single institution review, tried to clarify what adjuvant therapy would have the most benefit. This retrospective study compared ob- servation of 343 patients, who were placed in 1 of 3 categories: surgery alone, adjuvant CT with gemcitabine, or adjuvant 5-FU based CT-RT after surgical resection. Median follow-up and median survival for all patients were 17.5 and 19.5 months, respectively. Median survival was 13, 23 and 26 months, locoregional recurrence was 60\%, $63 \%$, and $38 \%$ and distant failure was $64 \%, 65 \%$, and $66 \%$ for surgery, adjuvant CT and adjuvant CT-RT, respectively. Adjuvant 5-FU based CT-RT significantly decreased locoregional recurrence. Compared to adjuvant CT alone, adjuvant CT-RT improved survival in patients with resected pancreatic cancer.

Interesting findings were provided by an analysis published in 2014, performed among 705 patients who were identified by use of the Surveillance, Epidemiology and End Results (SEER) Medicare database. It revealed that outcomes for patients, who received adjuvant CT-RT with either gemcitabine of 5-FU did not differ. However, in a group of patients suffering from moderately differentiated tumors, chemotherapy based on 5-FU produced better outcomes compared to CT-RT based on 5-FU. Contrary results were obtained in poorly differentiated tumors [33].

The quest for optimal adjuvant therapy continues, and the use of the oral agent S-1 in an adjuvant setting represents one of the newer successes in this direction [34]. The result of the Fukutomi et al. trial [35] are likely to influence the design of future clinical trials in Asia and beyond as similar trials assessing the utility of S-1 in an adjuvant setting are likely to be designed for European and North American populations. Murakami et al. [36] reported that long-term results of adjuvant gemcitabine plus S-1 chemotherapy after surgical resection for pancreatic carcinoma may be safe and promising as treatment for this patient population [36].

It should be underlined that pancreatic cancer patients recruited to the clinical trials differ from the population of patients treated in everyday practice in terms of age, general condition and comorbidities. These differences have a great influence on the tolerance of treatment, perceived toxicity and achieved results of therapy. Below examples of tolerance and outcomes of adjuvant CT-RT in two pancreatic cancer patients treated in the our institution are presented.

\section{Case No. 1}

A 56-year old male patient underwent radical surgery according to Whipple's method. A grossly evident residual status (R2) was achieved. Histopathological examination revealed $2 \mathrm{~cm}$ in diameter ductal adenocarcinoma of the head of the pancreas in G2 degree of malignancy with duodenum infiltration, perineural invasion and extrapancreatic extension. The clinical stage of the disease assessed postoperatively was T3N1MO. At the beginning of adjuvant treatment administration the patients' performance status (PS) was good (WHO-1). The patient suffered from various comorbidities, including arterial hypertension, nonalcoholic hepatic steatosis, mild anaemia and prior gastric resection. The interval between radical surgery and the beginning of adjuvant CT was 43 days. The patient 
underwent 6.5 courses of CT based on gemcitabine 1800 $\mathrm{mg}$, administered intravenously on days 1,8 , and 15 every 4 weeks. RT was started with the $3^{\text {rd }}$ course of CT treatment. The patient received 1.5 courses of CT during RT followed by 2 courses of CT alone. Radiotherapy to the tumor bed and regional lymph nodes in the total dose of $50.4 \mathrm{~Gy}$ was given within 28 fractions. During the treatment hematological toxicity in the form of G1 thrombocytopenia, G2 leukopenia, G1 anaemia and G1 cardiac toxicity was observed. Thrombocytopenia led to 3 systemic treatment interruptions (postponing CT continuation by one week). Adverse complaints from the upper gastrointestinal tract (upper GI) in the form of G1 nausea and G1 vomiting were observed as well. The patient experienced $\mathrm{G} 2$ toxicity from the lower gastrointestinal tract (lower GI), in the form of abdominal pain and diarrhea. During the treatment the patient gained $12 \mathrm{~kg}$, and experienced pain of moderate intensity. One month after cessation of adjuvant CT-RT, control computed tomography revealed recurrence in the tumor bed.

\section{Case No. 2}

A 65-year old male patient underwent radical surgery according to the Traverso technique. Microscopic residual tumor resection (R1) was achieved. Histopathological examination revealed $5 \mathrm{~cm}$ in diameter ductal adenocarcinoma of the head of the pancreas. The clinical stage of the disease assessed postoperatively was T2N1M0. Although PS according to WHO criteria was 0, the patient suffered from various comorbidities, such as: arterial hypertension, hepatic steatosis, diabetes type 3, malnutrition and anaemia. The interval between radical surgery and the beginning of adjuvant CT was 44 days. The patient underwent 4.5 courses of CT based on gemcitabine 2000 mg administered intravenously in a modified regimen on days 1 and 7 every 3 weeks due to toxicity and lack of the patient's cooperation. RT was started with the $3^{\text {rd }}$ course of CT treatment, then the patient received one course of $\mathrm{CT}$ during RT and completed the adjuvant treatment. Radiotherapy to the tumor bed and regional lymph nodes in the total dose of 45 Gy was given in 25 fractions. Haematological toxicity in the form of G1 thrombocytopenia, G2 neutropenia, and G2 anaemia was observed in the patient. This toxicity led to 2 systemic treatment interruptions (postponing the subsequent course of CT infusion for a week). Adverse complaints from the upper Gl and the lower G1, both of G2 intensity, were observed. Weight loss of $7.5 \mathrm{~kg}$ was observed and the patient experienced pain of moderate intensity [37]. Two months after cessation of adjuvant CT-RT, control computed tomography detected liver metastases. Moreover, the patient experienced G3 cardiac toxicity (right ventricular failure and pulmonary embolism 5 months after the end of adjuvant (T-RT) and was treated in the Department of Invasive Cardiology Teaching Hospital of the Medical University of Bialystok, Poland.

\section{Toxicity of adjuvant chemo-radiotherapy}

Adverse effects of adjuvant CT-RT in pancreatic cancer patients may decrease the quality of patients' lives. What is more, CT-RT tolerance in everyday clinical practice may be more frequently observed and be more severe than that observed in clinical studies due to the non-uniform patients' population. Even in published results of different studies data concerning not only treatment results but its tolerability are confusing.

Hematological toxicity is very common in pancreatic cancer patients treated with gemcitabine-based CT. What is more, G3-4 hematological toxicity occurs more frequently in CT-RT followed by gemcitabine than CT-RT followed by 5-FU [38]. Based on currently available evidence from the available literature, CT based on gemcitabine was generally well tolerated. In Oettle's randomized study [14] G1-2 (30.8\% of patients) and G3 (2.4\% of patients) hematological toxicities occurred, but did not decrease the patients' quality of life. However, other studies revealed that G3 or G4 neutropenia was frequently experienced (in $56 \%$ and $14 \%$ of patients, respectively) [39]. Most myelosuppression resolved effectively without complications [39]. What is more, administration of gemcitabine to patients after surgical pancreatic tumor resection caused more severe neutropenia, as compared to non-resected patients [40]. In other studies G3 thrombocytopenia was experienced in $0.5-2 \%$ and G4 thrombocytopenia in $0.3 \%$ of pancreatic cancer patients $[12,14,39]$. Anemia of G2 intensity was detected in $25 \%$ of pancreatic cancer patients, while G3 was detected in 3.5-5\% and G4 in 20\% of the patients [12, 39].

Radiation toxicity may not be well tolerated, even with very carefully planned, sophisticated 3D radiation therapy, in which the tolerance doses for critical organs are not exceeded and the best adjunctive treatment is delivered to the patients [41].

Nausea, even of G4 severity, was reported in the majority of patients [12, 14, 16, 18, 29, 39, 41, 42], whereas in Regine's study [29] nausea and vomiting were observed only in $10 \%$ of the patients, mainly treated with gemcitabine. In some cases $\mathrm{G} 3$ vomiting required hospitalization [43]. Mucous membrane toxicity or stomatitis of G3 or higher grade of toxicity was also reported in $10 \%$ of patients treated with gemcitabine [29]. Diarrhea, which affected $15 \%$ of the patients in the gemcitabine group, was documented as well [29]. A frequent side effect of adjuvant treatment in pancreatic cancer patients is weight loss, which is reported in $23-61 \%$ of patients [12, 41].

Nevertheless, there is a lack of medical literature data concerning cardiac toxicity, and it is considered to be very rare (less than $10 \%$ of patients) [29]. However, this kind of toxicity should be known, since it can cause serious consequences (e.g. in case 2). Unfortunately, to date there is insufficient information in published studies concerning experienced pain accompanying the treatment. The problem is probably underestimated, and more careful pain evaluation is needed.

\section{Pattern of failure}

Most treatment failures in pancreatic cancer patients are due to local recurrence, distant metastases, or both, and occur within one to two years after surgery [9]. In the study by Ueno and Kosuge study [39], at the time 
of analysis patients in the gemcitabine group and in the surgery-only group experienced recurrent disease. The common sites of first recurrence were the liver (30\%), peritoneum (18\%) and tumor bed (23\%). The rate of local recurrence alone as first progression was notably lower in the control arm of the EORTC-40013-22012/FFCD-9203/ GERCOR phase II trial compared to gemcitabine-based CTRT (experimental arm) (11\% vs. 24\%). The rate of simultaneous local and distant progression as first progression was $13 \%$ in the control arm vs. $20 \%$ in the experimental arm, and the rate of distant progression only was quite similar in both arms (40\% vs. 42\%).

\section{Summary}

In summary, to date it has been difficult to establish a definitive role for adjuvant CT-RT. These trials either are limited in size or have other methodological problems or no contemporary value [40]. What is more, long-term survival data after surgical resection are disappointing and only slightly improved by adjuvant therapy. Both local and distant recurrences are frequent and difficult to control. Tolerance of adjuvant chemo-radiotherapy is moderate as well. The review of the literature indicates that the combined treatment carries a risk of toxicity, which interferes with the treatment compliance. Careful qualification of pancreatic cancer patients for adjuvant CT-RT considering PS and comorbidities is strongly needed. Adjunctive treatment (including analgesic therapy) during adjuvant CT-RT in pancreatic cancer patients is needed as well. Postoperative adjuvant therapy in pancreatic cancer patients still remains a challenge, and there exist many intriguing open questions for future research, which among others concern the evaluation of diagnostic modalities in order to detect pancreatic cancer at an earlier stage of disease. In the era of better understanding of molecular characteristics of cancers, it is possible that it may help to define a group of patients, who would benefit from CT-RT. In this context it is interesting that pancreatic cancer patients with a high expression of hENT1 and hCNT3 immunostaining have significantly longer survival after adjuvant gemcitabine-based CT-RT [44, 45]. Defining predictive and prognostic factors for better selection of pancreatic cancer patients for different forms of adjuvant therapy is awaited.

Further investigation and progress in these new strategies are expected in the future. As well as developing new effective treatments, individualized approaches based on differences in drug metabolism are also important in selecting patients who are more likely to benefit from adjuvant treatment based on gemcitabine.

The authors declare no conflict of interest.

\section{References}

1. Parkin DM, Bray F, Ferlay J, Pisani P. Global cancer statistics, 2002. CA Cancer J Clin 2005; 55: 74-108.

2. Didkowska J, Wojciechowska U, Zatoński WA. Nowotwory złośliwe w Polsce w 2011 roku. [Cancer in Poland in 2011] [Article in Polsih] Centrum Onkologii Instytut, Warszawa 2013.
3. Świeboda-Sadlej A, Heleniak H. Combined management of resectable and locally advanced pancreatic cancer - is there an optimal therapeutic model? Contemp Oncol (Pozn) 2008; 12: 121-7.

4. Conlon KC, Klimstra DS, Brennan MF. Long term survival after curative resection for pancreatic ductal adenocarcinoma. Clinicopathologic analysis of 5 - year survivors. Ann Surg 1996; 223 : 273-9.

5. Nehring P, Makowski A, Mrozikiewicz-Rakowska B, et al. Nowe spojrzenie na etiopatogenezę i diagnostykę raka gruczołowego trzustki. [A new look at the etiopathogenesis and diagnosis of adenocarcinoma of the pancreas] [Article in Polish]. Nowa Klin 2011; 1: 62-6.

6. Royal RE, Wolff RA, Crane CH. Pancreatic Cancer. In: DeVita VT, Hellman S, Rosenberg SA (eds.). Cancer: Principles and Practice of Oncology. 8th ed. Lippincott Williams \& Wilkins; Philadelphia 2008; 1086-124.

7. Kalser MH, Ellenberg SS. Pancreatic cancer: adjuvant combined radiation and CT following curative resection. Arch Surg 1985; 120 : 899-903.

8. Kumar A, Falk G, Stephans KL, et al. Adjuvant chemoradiation to improve survival compared to adjuvant chemotherapy in selected patients with pancreatic cancer. 2014 Gastrointestinal Cancers Symposium. J Clin Oncol 2014; 32 (suppl 3): abstr 330.

9. Neoptolemos JP, Stocken DD, Friess H, et al. A randomized trial of chemoradiotherapy and $\mathrm{CT}$ after resection of pancreatic cancer. N Engl J Med 2004; 350: 1200-10.

10. Morak MJ, van der Gaast A, Incrocci L. Adjuvant intra-arterial CT and radiotherapy versus surgery alone in resectable pancreatic and periampullary cancer: a prospective randomized controlled trial. Ann Surg 2008; 248: 1031-41.

11. Idasiak A, Wolny E, Wydmański J, et al. Zastosowanie konformalnej radioterapii i modulacji intensywności wiązki w planowaniu pooperacyjnej radioterapii chorych na raka trzustki. [The comparison of conformal radiotherapy with intensity - modulated radiotherapy for post-operative adjuvant radiation for patients with pancreas carcinoma] [Article in Polish]. Contemp Oncol (Pozn) 2004; 8: 347-52.

12. Van Laethem JL, Hammel P, Mornex F, et al. Adjuvant gemcitabine alone versus gemcitabine-based chemoradiotherapy after curative resection for pancreatic cancer: a randomized EORTC-40013-22012/FFCD-9203/GERCOR Phase II Study. J Clin Oncol 2010; 28: 4450-6.

13. Sohn TA, Yeo CJ, Cameron JL, et al. Resected adenocarcinoma of the pancreas - 616 patients: results, outcomes, and prognostic indicators. J Gastrointest Surg 2000; 4: 567-79.

14. Oettle H, Post S, Neuhaus P, et al. Adjuvant CT with gemcitabine vs. observation in patients undergoing curative-intent resection of pancreatic cancer: a randomized controlled trial. JAMA 2007; 297: 267-7.

15. Saif MW. Adjuvant therapy of pancreatic cancer: beyond gemcitabine. 2011 ASCO Gastrointestinal Cancers Symposium 2011; 12: 106-9.

16. Liao WC, Chien KL, Lin YL, Wu MS, Lin JT, Wang HP, Tu YK. Adjuvant treatments for resected pancreatic adenocarcinoma: a systematic review and network meta-analysis. Lancet Oncol 2013; 14: 1095103.

17. Verslype C, Van Cutsem E, Dicato M. The management of pancreatic cancer. Current expert opinion and recommendations derived from the 8th World Congress on Gastrointestinal Cancer, Barcelona, 2006. Ann Oncol 2007 (Suppl. 7): 1-10.

18. Klinkenbijl JH, Jeekel J, Sahmoud T, et al. Adjuvant radiotherapy and 5-flourouracil after curative resection of cancer of pancreas and periampullary region: phase III trial of EORTC gastrointestinal tract cancer cooperative group. Ann Surg 1999; 230: 776-82.

19. Smeenk G, van Eijck CH, Hop WC, et al. Long-term survival and metastatic pattern of pancreatic and periampullary cancer after adjuvant chemoradiation or observation: Long-term results of EORTC trial 40891. Ann Surg 2007; 246: 734-40.

20. Yeo CJ, Abrams RA, Grochow LB, et al. Pancreaticoduodenectomy for pancreatic adenocarcinoma: postoperative adjuvant chemoradiation improves survival. A prospective, single-institution experience. Ann Surg 1997; 225: 621-3. 
21. Herman JM, Swartz MJ, Hsu CC, et al. Analysis of fluorouracil-based-adjuvant CT and radiation after pancreaticoduodenectomy for ductal adenocarcinoma of the pancreas: results of a large, prospectively collected database at the Johns Hopkins Hospital. J Clin Oncol 2008; 26: 3503-10.

22. Hsu CC, Herman JM, Corsini MM, et al. Adjuvant chemoradiation for pancreatic adenocarcinoma: the Johns Hopkins Hospital-Mayo Clinic collaborative study. Ann Surg Oncol 2010; 17: 981-90.

23. Neoptolemos JP, Dunn JA, Stocken DD, et al.; European Study Group for Pancreatic Cancer. Adjuvant chemo radiotherapy and $\mathrm{CT}$ in resectable pancreatic cancer: a randomized controlled trial. Lancet 2001; 358: 1576-85.

24. Katz MH, Fleming JB, Lee JE, Pisters PW. Current status of adjuvant therapy for pancreatic cancer. Oncologist 2010; 15: 1205-13.

25. Burris HA, Moore MJ, Andersen J, et al. Improvements in survival and clinical benefit with gemcitabine as first-line therapy for patients with advanced pancreas cancer: a randomized trial. J Clin Oncol 1997; 15: 2403-13.

26. Berlin JD, Catalano P, Thomas JP, Kugler JW, Haller DG, Benson II AB Phase III study of gemcitabine in combination with fluorouraci versus gemcitabine alone in patients with advanced pancreatic carcinoma: Eastern Cooperative Oncology Group Trial E2297. J Clin Oncol 2002; 20: 3270-5.

27. Rocha Lima CM, Green MR, Rotche R, et al. Irinotecan plus gemcitabine results in no survival advantage compared with gemcit abine monotherapy in patients with locally advanced or metastat ic pancreatic cancer despite increased tumor response rate. I Clin Oncol 2004; 22: 3776-83.

28. Yu Z, Zhong W, Tan ZM, et al. Gemcitabine adjuvant therapy for resected pancreatic cancer: a meta-analysis. Am J Clin Oncol 2015; 38: 322-5.

29. Regine WF, Winter KA, Abrams RA. Fluorouracil vs. gemcitabine CT before and after fluorouracil-based chemoradiation following resection of pancreatic adenocarcinoma: a randomized controlled trial. JAMA 2008; 299: 1029-6.

30. Neoptolemos J, Büchler M, Stocken DD, et al. ESPAC-3(v2): a multicenter, international, open-label, randomized, controlled phase II trial of adjuvant 5-fluorouracil/folinic acid (5-FU/FA) versus gemcitabine (GEM) in patients with resected pancreatic ductal adenocarcinoma. J Clin Oncol 2009; 27 (Suppl.): abstract LBA4505.

31. Regine WF, Winter KA, Abrams R, et al. Fluorouracil-based chemoradiation with either gemcitabine or fluorouracil chemotherapy after resection of pancreatic adenocarcinoma: 5-year analysis of the U.S. Intergroup/RTOG 9704 phase III trial. Ann Surg Oncol 2011; 18: 1319-26.

32. Oettle H, Neuhaus P, Hochhaus A, et al. Adjuvant chemotherapy with gemcitabine and long-term outcomes among patients with resected pancreatic cancer: the CONKO-001 randomized trial. JAMA 2013; 310: 1473-81.

33. Kizilbash SH, Ward KC, Liang JJ, et al. Survival outcomes in patients with early stage, resected pancreatic cancer - a comparison of gemcitabine- and 5-fluorouracil-based chemotherapy and chemoradiation regimens. Int J Clin Pract 2014; 68: 578-89.

34. Yoshitomi $\mathrm{H}$, Shimizu $H$, Yoshidome $H$. A randomized phase II trial of adjuvant chemotherapy with S-1 versus S-1 and gemcitabine (GS) versus gemcitabine alone (GEM) in patients with resected pancreatic cancer (CAP-002 study). J Clin Oncol 2013; 31 (Suppl.): abstract 4056.

35. Uesaka K, Fukutomi A, Boku N, Kanemoto H, et al. Randomized phase III trial of adjuvant chemotherapy with gemcitabine versus S-1 for patients with resected pancreatic cancer (JASPAC-01 study). J Clin Oncol 2012; 30 (Suppl.): abstract 145.

36. Murakami Y, Uemura K, Sudo T, et al. Long-term results of adjuvant gemcitabine plus S-1 chemotherapy after surgical resection for pancreatic carcinoma. J Surg Oncol 2012; 106: 174-80.

37. Dobrogowski J, Krajnik M, Jassem J, Wordliczek J. Stanowisko dotyczące postępowania przeciwbólowego u chorych na nowotwory. [Consensus statement with focus on cancer pain management] [Article in Polish]. Onkol Prakt Klin 2009; 5: 55-68.

38. Liao WC, Chien KL, Lin YL, Wu MS, Lin JT, Wang HP, Tu YK. Adjuvant treatments for resected pancreatic adenocarcinoma: a systematic review and network meta-analysis. Lancet Oncol 2013; 14: 1095 103.

39. Ueno H, Kosuge T, Matsuyama Y. A randomised phase III trial comparing gemcitabine with surgery-only in patients with resected pancreatic cancer: Japanese study group of adjuvant therapy for pancreatic cancer. Br J Cancer 2009; 101: 908-15.

40. Onoue M, Terada T, Okuda M, Fujimoto K, Doi R, Imamura M, Inui K. Surgical resection deteriorates gemcitabine-induced leukopenia in pancreatic cancer. Int J Clin Oncol 2004; 9: 174-8.

41. Wang ML, Foo KF. Adjuvant chemoradiotherapy for high-risk pancreatic cancer. Singapore J 2009; 50: 43-8.

42. Rożnowski K, Ramlau C. Ocena skuteczności i tolerancji gemcytabiny w leczeniu zaawansowanego raka trzustki - doniesienia wstępne. [Evaluation of efficacy and safety of gemcytabine in the treatment of advanced pancreat cancer - a preliminary report] [Article in Polish]. Nowotwory 1999; 49: 46-52.

43. Allen AM, Zalupski MM, Robertson JM, et al. Adjuvant therapy in pancreatic cancer: phase I trial of radiation dose escalation with concurrent full-dose gemcitabine. Int Phys 2004; 59: 1461-7.

44. Farrell J, Elsaleh H, Garcia M, Lai R, et al. Human equilibrative nucleoside transporter 1 levels predict response to gemcitabine in patients with pancreatic cancer. Gastroenterology 2009; 136: 187 95.

45. Maréchal R, Mackey JR, Lai R, et al. Human equilibrative nucleoside transporter 1 and human concentrative nucleoside transporter 3 predict survival after adjuvant gemcitabine therapy in resected pancreatic adenocarcinoma. Clin Cancer Res 2009; 15: 2913-9.

\section{Address for correspondence}

\section{Ewa Sierko}

Department of Oncology, Medical University of Bialystok Comprehensive Cancer Center

Ogrodowa 12

15-027 Bialystok, Poland

tel. +48856646734

e-mail: ewa.sierko@iq.pl

Submitted: 28.04 .2014

Accepted: 19.03 .2015 